\title{
Mulheres rurais e o protagonismo no desenvolvimento rural: um estudo no município de Vitorino, Paraná
}

\author{
Rural women and their protagonism in rural development: a study in the \\ municipality of Vitorino, Paraná \\ Mujeres rurales y protagonismo en el desarrollo rural: un estudio en el \\ municipio de Vitorino, Paraná
}

\author{
Clair Odete Schneider ${ }^{1}$ \\ Cristiane Maria Tonetto Godoy ${ }^{1}$ \\ Josiane Carine Wedig ${ }^{1}$ \\ Thiago de Oliveira Vargas ${ }^{1}$
}

Recebido em 09/05/2019; revisado e aprovado em 19/06/2019; aceito em 25/07/2019.

DOI: http://dx.doi.org/10.20435/inter.v21i2.2560

\begin{abstract}
Resumo: As mulheres rurais vêm ganhando espaço nos debates e nas formulações das políticas públicas, bem como reconhecimento para o fortalecimento da agricultura familiar e para o desenvolvimento rural sustentável. Nesse sentido, o presente artigo tem como objetivo compreender a percepção sobre o papel e a representatividade das mulheres rurais no município de Vitorino, estado do Paraná. A metodologia adotada para o levantamento dos dados foi qualitativa, por meio de vinte e duas entrevistas semiestruturadas com agricultores familiares do município, conjuntamente com o apoio de uma revisão bibliográfica sobre a temática. De acordo com os resultados apurados, pode ser aferida a existência do êxodo das mulheres jovens para os centros urbanos, consequentemente ocasionando o fenômeno do envelhecimento da população do campo. Em relação à divisão de trabalho, pode ser percebido que as concepções existentes ainda são masculinizadas no que se refere à divisão e hierarquização do trabalho feminino na propriedade. Nesse sentido, apesar de existir um incentivo e mudança na sociedade no que tange às conquistas femininas, ainda é possível encontrar espaços onde existe a separação dos papéis pelo gênero. Assim, torna-se de suma importância repensar meios e alternativas para assegurar a participação efetiva na gestão da propriedade, além de fomentar os cursos e a assistência técnica para que esses atendam às necessidades das mulheres rurais, pois somente assim teremos o desenvolvimento rural em sua totalidade.
\end{abstract}

Palavras-chave: mulheres; percepção; desenvolvimento rural.

Abstract: Rural women have been gaining ground in the debates and formulations of public policies, as well as their recognition for the strengthening of family farming and sustainable rural development. In this sense, this article aims to understand the perception of the role and representativeness of rural women in the municipality of Vitorino, Paraná state. The methodology adopted for the data collection was qualitative, through twenty-two semi-structured interviews with the family farmers of the municipality, together with the support of a bibliographic review on the subject. According to the results, the existence of the exodus of young women to the urban centers can be verified, consequently causing the phenomenon of the aging of the female population in the countryside. Concerning the division of labor, it can be seen that the existing conceptions are still masculinized in what concerns the division and hierarchy of the feminine work in the property. In this sense, although there is an incentive and change in the society regarding the achievements of women, it is still possible to find spaces where there is still the separation of roles by gender. Thus, it becomes very important to rethink means and alternatives to ensure effective participation in property management, as well as to encourage courses and technical assistance so they can meet the needs of rural women, because only then will we have full rural development.

Keywords: women; perception; rural development.

Resumen: Las mujeres rurales vienen ganando espacio en los debates y en las formulaciones de las políticas públicas, así como su reconocimiento para el fortalecimiento de la agricultura familiar y para el desarrollo rural sostenible. En este sentido, el presente artículo tiene como objetivo comprender la percepción sobre el papel y la representatividad de las mujeres rurales en el municipio de Vitorino, estado de Paraná. La metodología adoptada para el levantamiento de los datos fue cualitativa, a través de veintidós entrevistas

\footnotetext{
${ }^{1}$ Universidade Tecnológica Federal do Paraná (UTFPR), Pato Branco, Paraná, Brasil.
} 
semiestructuradas con los agricultores familiares del municipio, junto con el apoyo de una revisión bibliográfica sobre la temática. De acuerdo con los resultados constatados, puede ser evaluada la existencia del éxodo de las mujeres jóvenes hacia los centros urbanos, consecuentemente ocasionando el fenómeno del envejecimiento de la población femenina en el campo. Con relación a la división de trabajo, puede ser percibido que las concepciones existentes todavía son masculinizadas en lo que se refiere a la división y jerarquización del trabajo femenino en la propiedad. En ese sentido, a pesar de existir un incentivo y cambio en la sociedad en lo que se refiere a las conquistas femeninas, aún es posible encontrar espacios donde aún existe la separación de los papeles por género. Así, se vuelve de suma importancia repensar medias y alternativas para asegurar la participación efectiva en la gestión de la propiedad, además de fomentar los cursos y la asistencia técnica para que estos atiendan a las necesidades de las mujeres rurales, pues solo así tendremos el desarrollo rural en su totalidad.

Palabras clave: mujeres; percepción; desarrollo rural.

\section{INTRODUÇÃO}

O meio rural nas últimas décadas tem sido um espaço que incorpora múltiplas funções. Assim, existem diversas discussões sobre a agricultura familiar como segmento social importante para o desenvolvimento rural sustentável. Nesse sentido, os temas relacionados com o êxodo rural, juventude rural, envelhecimento, masculinização e mulheres rurais têm sido o foco de pesquisas na tentativa de compreender as questões que permeiam a permanência e a reprodução da agricultura familiar e o desenvolvimento rural.

Segundo Silva e Schneider (2010), é recorrente na literatura a afirmação de que a agricultura familiar é responsável por aproximadamente $38 \%$ do valor bruto da produção dos alimentos consumidos internamente no Brasil, correspondendo a 85\% dos estabelecimentos agropecuários do país. Assim, fica evidente a importância da produção oriunda da agricultura familiar no abastecimento e segurança alimentar do país.

Outro aspecto em relação à agricultura familiar está no envolvimento de todo o núcleo familiar no trabalho e na gestão da unidade produtiva, não havendo a separação do tempo de trabalho e da família. Nesse contexto, para os autores supracitados, existe pouca pesquisa sobre o papel das mulheres rurais no que se refere a sua contribuição nas unidades familiares de produção, sendo esse um tema emergente e importante para reflexões sobre o desenvolvimento rural.

Apesar das conquistas adquiridas pelas mulheres nas últimas décadas, ainda é possível verificar no meio rural uma invisibilidade delas no que refere ao trabalho e à gestão, visto que elas são importantes protagonistas na efetivação de diversas atividades da propriedade e na manutenção da família. Nesse sentido, é necessário avançarmos no debate sobre a participação das mulheres nas propriedades rurais, e não apenas como coadjuvantes de seus maridos e/ ou pais.

É ao reconhecermos o protagonismo dessas mulheres e a necessidade de um maior conhecimento sobre suas contribuições nas propriedades rurais que propusemos este trabalho, que teve como objetivo compreender a percepção do papel social e da representatividade das mulheres rurais no município de Vitorino, estado do Paraná, PR. Assim, por meio desta pesquisa, esperamos contribuir com a ampliação dos estudos da temática sobre as mulheres rurais e do papel que exercem para o fortalecimento da agricultura familiar e para o desenvolvimento rural sustentável, além de auxiliar com mais informações para a formulação de políticas públicas que visem atender às necessidades desse segmento. 


\section{CONHECENDO A REGIÃO E O APORTE METODOLÓGICO}

A pesquisa foi realizada no município de Vitorino, localizado no Sudoeste do Paraná, que tem como divisa territorial os municípios de Pato Branco, Renascença, Bom Sucesso do Sul e Mariópolis. De acordo com o censo demográfico de 2010, o município possui uma população estimada em 6.513 habitantes, dividida em 3.230 homens e 3.283 mulheres. Em relação à divisão da população urbana e rural, existem 1.935 homens e 2.053 mulheres na área urbana e 1.295 homens e 1.230 mulheres na área rural (INSTITUTO PARANAENSE DE DESENVOLVIMENTO ECONÔMICO E SOCIAL [IPARDES], 2018).

A região do Sudoeste do Paraná é composta majoritariamente por propriedades familiares, consequência histórica da ocupação de terras. Em relação à economia, a região tem como característica a produção agropecuária voltada para os grãos (milho, soja e feijão) e a produção leiteira. Segundo Magalhães (2009), Schmitz e Santos (2013), o leite tem sido uma importante fonte de renda para as propriedades familiares da região, colocando o Sudoeste como segunda principal bacia leiteira do estado.

Para que possamos atingir o objetivo proposto neste trabalho, torna-se necessária uma metodologia que abarque a complexidade existente nas relações sociais e que constroem a realidade. Primeiramente, para compreendermos como se estabelece a percepção dos atores sociais, recorremos a Godoy (2015), que a define como aquela ação e efeito de perceber algo ou alguma coisa por meio de um de nossos sentidos, coletando assim informações e processando essas em forma de uma ideia sobre o objeto e o seu significado.

Para Oliveira (2009, p. 153), a percepção pode ser compreendida como nosso contato com o mundo exterior, tendo em vista que ela se dá por meio de nossos órgãos sensoriais de maneira seletiva e instantânea, o que nos proporciona a sensação, sendo variável, pois depende do órgão sensorial utilizado. Assim, as sensações passam por determinados filtros culturais e individuais para tornarem-se percepções. Além disso, "os filtros culturais e individuais são produtos do interesse, da necessidade e da motivação. São tão importantes, em nossa percepção, que muitas vezes determinam as tomadas das decisões e nos conduzem às tomadas de consciência" (OLIVEIRA, 2009, p. 153).

Conforme Bourdieu (1998), somos nós que construímos o espaço social por meio de pontos de vistas, contudo é claro que esses pontos serão diferentes ou até mesmo antagônicos, pois eles derivam da visão que cada agente tem do seu espaço, isto é, dependem da vivência de cada indivíduo. Dessa forma, a construção da visão do mundo dá-se por meio das coações estruturais que incidirão no habitus dos agentes, ou seja, é por meio das estruturas mentais que eles apreendem o mundo social, sendo assim, em essência, o produto da interiorização das estruturas do mundo social. Ainda, de acordo com o autor:

Assim, a busca de formas invariantes de percepção ou de construção da realidade social mascara diversas coisas: primeiramente, que essa construção não é operada num vazio social, mas está submetida a coações estruturais; segundo, que as estruturas estruturantes, as estruturas cognitivas, também são socialmente estruturadas, porque têm uma gênese social; terceiro, que a construção da realidade social não é somente um empreendimento individual, podendo também tornar-se um empreendimento coletivo. Mas a chamada visão microssociológica esquece muitas outras coisas: como acontece quando se quer olhar de muito perto, a árvore esconde a floresta [...]. (BOURDIEU, 1998, p. 158)

Assim, a percepção é uma ação subjetiva, não podendo ser medida e compreendida por meio de experimentos quantitativos. Nesse sentido, escolhemos como aporte metodológico 
a abordagem qualitativa típica das ciências sociais, sendo configurada pela compreensão e interpretação da realidade social e das relações que se estabelecem nesse universo e em seus significados. Para Goméz, Florez e Jiménez (1996), a pesquisa qualitativa é o retrato da vida de um grupo social, pois é possível descrever analiticamente o caráter interpretativo de uma estrutura social ou cultura. A partir dela, podemos construir de forma teórica esquemas que consigam responder o mais fiel possível às percepções e ações do grupo social estudado.

Para esta pesquisa, foram escolhidas as técnicas da entrevista semiestruturada e a observação participante. Justificamos a escolha dessas técnicas por entendermos que a observação participante permite a obtenção de informações sobre um fenômeno ou acontecimento tal e como ele se produz, pois as informações muitas vezes não podem ser percebidas somente por meio das falas, mas também por meio das ações dos indivíduos. A entrevista semiestruturada auxilia a obter informações dos indivíduos quanto a suas percepções, sentimentos e opiniões sobre determinado assunto.

Ainda em relação à pesquisa qualitativa, Gil (2010) explica que não existe a necessidade de processos estatísticos de amostragem e nem mesmo um grande número de entrevistas para garantir a representatividade, como é visto na metodologia quantitativa. De acordo com Turato (2003), a pesquisa qualitativa tem como característica aprofundar a compreensão sobre o objeto estudado de uma maneira específica, mas possui a limitação da compreensão no que se refere à extensão. Corroborando com esta concepção, Ribeiro, Souza e Lobão (2018) afirmam que não existe um regramento que determine a quantidade específica de dados para as pesquisas de cunho qualitativo. Nesse tipo de metodologia, a informação que se busca não está propriamente na quantidade do número de entrevistas, e sim na qualidade, profundidade e na extensão das respostas dadas pelos(as) entrevistados(as).

Nesse sentido, foram realizadas entrevistas semiestruturadas com vinte e dois agricultores familiares do município de Vitorino, PR. A amostragem desses agricultores não foi pautada em nenhum estilo estatístico. Os agricultores entrevistados foram todos aqueles que participavam das palestras propiciadas nesse dia pela Prefeitura Municipal juntamente de docentes do curso de Agronomia da Universidade Tecnológica Federal do Paraná, campus Pato Branco. As palestras tiveram como temáticas: bem-estar animal, os sistemas de produção-criação e os prós e contras no sistema leiteiro; e análises dos solos de Vitorino, questões sobre conservação e uso do solo no município.

As perguntas constantes no roteiro de entrevista estavam relacionadas aos aspectos sociais, econômicos e ambientais dos agricultores familiares e suas propriedades. Para este artigo, além das perguntas gerais quanto a tamanho da propriedade, composição familiar, produção para comercialização e consumo, foram analisadas também as seguintes questões: 1- Na sua propriedade, quem é responsável: (marido, esposa, filhos) pelo leite, horta, lavoura, trabalho doméstico e a comercialização? E por que ocorre essa divisão? 2- Quem realiza os cursos que são fornecidos pelo SENAR, SENAC, Prefeitura, EMATER, SENAE, entre outros? Quais são os cursos realizados? 3- O que você entende por lazer? O que você faz para descansar e se divertir? E os demais membros da família? 4- Quais as opções de lazer na comunidade (família, idosos, jovens, mulheres)? Quais as opções de lazer que o município proporciona? O que falta e o que seria bom ter na comunidade?

Dessa forma, para as análises das respostas, foram seguidos e estruturados os seguintes passos: (a) o contexto do discurso, analisando os sentidos e significados das respostas dos 
agricultores; e (b) a interpretação das percepções pelos pesquisadores e a articulação com outros estudos e pesquisas. Cabe salientar que as respostas analisadas dizem respeito às percepções dos entrevistados, validando essa compreensão para o público que participou da pesquisa e não expandindo para os agricultores familiares em geral, já que cada comunidade e região apresenta uma realidade distinta.

\section{MULHERES RURAIS NO MUNICÍPIO: ALGUMAS REFLEXÕES}

Com a modernização da agricultura, podemos aferir que houve importantes transformações produtivas e sociais no meio rural, impactando assim o modo de vida e a relação com o mercado. Anteriormente, a agricultura estava baseada em uma produção diversificada e para o autoconsumo, porém, no novo modelo de agricultura, a produção está voltada para produtos homogeneizados e industrializados. É também na modernização que se inicia a valorização dos centros urbanos em relação ao rural, relegando a esse espaço somente a produção agropecuária.

Porém o rural não é apenas um espaço de produção, ele é palco de multifuncionalidades e pluriatividades, além das relações sociais existentes. É a partir desse reconhecimento que podemos observar a ampliação na discussão sobre a importância da agricultura familiar para o desenvolvimento rural sustentável do país. Isso fica evidente na formulação de diversas políticas públicas para esse segmento e nos vários trabalhos acadêmicos de análise desta categoria social. Nesse contexto, nas últimas décadas tivemos a inclusão e discussão sobre as questões de gênero, direcionadas, sobretudo, ao estudo dos papéis sociais, direitos e participação das mulheres rurais na gestão das propriedades.

De acordo com Silva e Mendes (2014), a produção familiar está baseada, principalmente, nas dinâmicas de trabalho, no vínculo familiar e nas questões culturais. Para Magalhães (2009), é importante analisarmos as relações de gênero, pois somente assim poderemos compreender a realidade das mulheres na sociedade, inclusive no espaço rural. Corroborando com Menasche e Escher (1996), ao abordarem os papéis sociais desempenhados pelas mulheres na sociedade moderna, é possível observar que esses são marcados por inúmeras lutas na busca pelo acesso de direitos e reconhecimento enquanto cidadãs. Para as mulheres rurais, essas lutas também estão ligadas às reivindicações pela visibilidade e valorização de seu trabalho, bem como do reconhecimento enquanto trabalhadoras.

No contexto da agricultura familiar, a produção depende diretamente da mão de obra familiar. De acordo com Silva e Mendes (2015, p. 229), "a produção familiar corresponde a uma unidade de produção agrícola onde há relações com o espaço e com as dinâmicas do sistema de trabalho, no vínculo entre a família e seu entorno sociocultural". Nesta estrutura familiar, conforme as autoras, as mulheres rurais têm papel fundamental, pois cabe a elas a responsabilidade da sobrevivência e reprodução.

A unidade de produção familiar é formada por homens e mulheres de diferentes idades, que possuem diferentes formas de perceber a vida e objetivos diversos. Dessa forma, é comum ocorrerem subdivisões e designações para a realização das atividades e, em muitos casos, essa divisão está fortemente marcada pela divisão sexual do trabalho, havendo distinções sobre o que é o trabalho do homem, da mulher e dos filhos e das filhas.

Para compreendermos as relações existentes nas famílias agricultoras que participaram desta pesquisa, primeiramente analisamos quais as atividades produtivas que são exercidas nas propriedades. Neste sentido, foram identificadas a produção de grãos (lavoura), de leite e 
de hortaliças. De acordo com Neves et al. (2011), para compensar as dificuldades e os preços pagos na lavoura, muitas propriedades rurais veem na produção leiteira uma alternativa para complementar a renda.

Nesse contexto, perguntamos aos entrevistados quem são os/as responsáveis pelo rebanho e pela produção leiteira nas propriedades. Nesse sentido, as respostas apontaram para: duas propriedades em que apenas as mulheres são responsáveis pela atividade; uma propriedade na qual apenas o homem é o responsável; 11 propriedades em que todos os membros da família são os responsáveis; e 8 propriedades em que os entrevistados não possuem produção leiteira.

A produção leiteira é a principal renda das famílias rurais, já que é capaz de gerar mais rendimentos e as entradas são mensais, ao contrário da produção de grãos que dependem da época de colheita (SCHMITZ; SANTOS, 2013). Para Paulilo, Grandi e Silva (2016, p. 161), "a atividade leiteira sempre foi uma atividade predominantemente feminina, tanto no Brasil como em outras regiões do mundo".

Entretanto, nas respostas obtidas em nossa pesquisa, a atividade leiteira não é mais somente feminina; ao contrário, na maioria das respostas, evidenciou-se que tanto homens quanto mulheres se fazem presentes nessa atividade produtiva. No trabalho de Neves et al. (2011), foi encontrado que a participação das mulheres na pecuária leiteira era de 42,8\%.

Porém Schmitz e Santos (2013) apontam que as mulheres perdem espaços na gestão da atividade após a modernização na produção leiteira. Magalhães (2009) demonstra que, quando a produção leiteira se destaca como produção significativa na formação da renda da propriedade, o domínio passa para o controle masculino. Em outras palavras, o autor conclui que, quando a produção de leite passa a gerar lucro, ela muda de domínio, sendo reforçada pela modernização e reestruturação dos mercados, adentrando o ambiente de domínio masculino.

O público presente no dia das palestras foi de 22 homens, não havendo nenhuma mulher presente, mesmo como acompanhante. Eram palestras de cunho técnico, incluindo uma sobre manejo e boas práticas para o rebanho bovino leiteiro. Como observamos em nosso contexto de pesquisa, a participação nos espaços de formação técnica sobre bovinocultura leiteira é apenas de homens, que seriam os responsáveis por repassar as informações às mulheres. Nesse aspecto, cabe questionar: como é possível (re)pensar o papel social da mulher rural na produção e sua representatividade se apenas o marido ou o filho frequentam os espaços de informações? Como pensar no empoderamento e desenvolvimento rural nessas circunstâncias?

Para Silva e Mendes (2015), as participações dos homens nas organizações são, geralmente, maiores que as das mulheres, com exceção naqueles espaços tidos como femininos, tais como: igrejas, quermesses, trabalhos comunitários e outros. Ainda, Heck e Langdon (2002) observaram que às mulheres são destinados os espaços coletivos, como clube de mães, reuniões de saúde, entre outros, ou seja, atividades relacionadas ao cuidado, classificadas como incumbência das mulheres. Já para os homens se destinam os espaços técnico-produtivos.

Para as mulheres, as possibilidades de participação na sociedade são mais restritas, considerando que os espaços de formação e capacitação não oferecem garantia de sua participação. E é por meio da participação que os sujeitos constroem as relações pessoais e sociais, possibilitando as trocas de experiências e os novos aprendizados (BATTISTI, 2014). Nesse sentido, os órgãos responsáveis pela assistência técnica e extensão rural devem propiciar ambientes de participação a todas e a todos os atores sociais do rural, não apenas aos homens considerados como chefe da família e da produção. 
Retomando a análise das entrevistas, realizamos a compilação da unidade familiar na sua composição no que tange à representatividade de homens e mulheres, separando por faixa etária, conforme apresentado pela Tabela 1. Cabe salientar que consideramos a unidade familiar composta pelos membros que permanecem no campo, sendo excluídos aqueles que foram declarados como residentes nos centros urbanos.

Tabela 1 - Unidade Familiar dos entrevistados por categorização de faixa etária

\begin{tabular}{llllllll}
\hline Gênero & $\mathbf{0 - 1 5}$ & $\mathbf{1 6 - 2 5}$ & $\mathbf{2 6 - 3 5}$ & $\mathbf{3 6 - 4 5}$ & $\mathbf{4 6 - 5 5}$ & $\mathbf{5 6 - 6 5}$ & $\mathbf{6 6} \mathbf{>}$ \\
Mulheres & 7 & 2 & 7 & 5 & 6 & 8 & $4=37$ \\
Homens & 4 & 8 & 4 & 6 & 5 & 8 & $6=41$ \\
Total $=$ & 78 pessoas & & & & \\
\hline
\end{tabular}

Fonte: Autores (2019).

Por meio da compilação dos dados dos/das integrantes das famílias entrevistadas, podemos realizar algumas reflexões sobre a presença das mulheres rurais no município de Vitorino. Podemos perceber que a diferença entre homens e mulheres que permanecem no rural é mínima, o total de mulheres declaradas foi de 37, já para os homens o total foi de 41 . Porém, quando observamos as faixas etárias, podemos perceber algumas diferenças existentes e que nos possibilitam refletir acerca do que pode ocorrer nesse espaço rural.

Ao analisarmos a faixa etária dos 16 a 25 anos, podemos aferir que é a faixa em que se tem o maior êxodo dos jovens, principalmente das mulheres. Durante as entrevistas, foi relatado pelos agricultores que as filhas saem de casa para estudar, trabalhar e/ou morar na cidade, ficando apenas alguns filhos homens. Eles afirmam que poucos jovens ficam na propriedade, muitas vezes atraídos por cursos e formações sem nenhuma ligação com a agropecuária e, com isso, mais voltados ao trabalho na cidade.

Segundo Ferreira e Alves (2009), são recorrentes, nas diversas pesquisas sobre a juventude rural, a constatação da predominância da saída das moças das áreas rurais, o que vem causando a masculinização do campo. Para os autores, essa saída seria causada pela condição subalterna das mulheres nas relações familiares, pela desvalorização delas no trabalho agropecuário, pela invisibilidade e desvalorização do trabalho doméstico e pelo pouco espaço como protagonistas nas atividades agropecuárias.

Para Paulilo (2004), uma das questões que promovem o êxodo das mulheres está relacionada ao acesso a terra, pois as filhas de agricultores não partilham de forma igualitária a herança com seus irmãos homens. Em muitos casos, as mulheres são incentivadas a se dedicarem aos estudos e buscarem renda fora do contexto rural, enquanto aos homens é oferecido o incentivo para a permanência na propriedade e sucessão das atividades da família. De acordo com Stropasolas (2004), as conquistas alcançadas pelas mulheres urbanas têm contribuído para o êxodo rural feminino, uma vez que o egresso delas para estudarem e as vivências experimentadas nos espaços urbanos as colocam em uma posição de reconhecimento e de valorização em comparação com a vida no meio rural.

Já para Froehlich et al. (2011), com a formulação das políticas públicas voltadas para o rural e para a agricultura familiar, houve aumento das possibilidades de permanência no rural, principalmente para os idosos, a exemplo da aposentadoria rural. Porém, ainda para muitos jovens rurais, as dificuldades de acesso à escolaridade e valorização da agricultura familiar são motivos para migrarem para os centros urbanos, principalmente as mulheres. 
Retomando os dados apresentados na Tabela 1, podemos também perceber que a maioria das mulheres se encontra nas faixas etárias de 26 a 35 anos, 46 a 55 anos e de 56 a 65 anos, sendo essa última faixa etária a que mais tem representantes -8 mulheres. Assim, podemos aferir que a população feminina rural do município está envelhecida. No estudo realizado por Camarano (2003) sobre os indicadores das condições de vida no meio rural, apareceu o predomínio das mulheres idosas, principalmente na faixa etária acima dos 80 anos, além de existir uma maior proporção de viúvas, fenômeno denominado como feminização da velhice. Ainda, para a autora, no ano de 1980 a expectativa de vida feminina era de 65 anos, 6,4 mais alta do que a masculina. E, se compararmos com o ano 2000, essa expectativa aumentou para 8,7 anos.

Apesar de termos o número de idosos homens e mulheres semelhantes, durante as entrevistas foi diagnosticado que quatro mulheres na faixa etária acima dos 66 anos estão morando com os filhos ou filhas nas propriedades, o que nos leva à hipótese de que essas idosas são viúvas e/ou separadas. Nesse contexto, Heck e Langdon (2002) refletem que o envelhecimento deixa de ser somente uma fase biológica e passa a ter diversas construções sociais, já que as idosas rurais se readaptarão, incluindo-se socialmente. Assim, pode ser percebido que essa readaptação é na verdade a ida dessas idosas para a casa dos filhos(as), saindo da sua propriedade.

Já em relação à presença de viúvas, Salgado (2002) aponta que há uma desigualdade de gênero na expectativa de vida de homens e mulheres, em que elas vivem em média sete anos a mais que os homens, resultando uma população expressiva de mulheres idosas no rural. Para Alcântara (2009), a predominância de mulheres viúvas no meio rural está relacionada, principalmente, ao fato de os homens permanecerem expostos por mais tempo aos agrotóxicos utilizados na produção, acarretando doenças e morte. Segundo Augusto e Ribeiro (2005), nosso país possui uma população jovem feminina rural cada vez menor, em contrapartida existe um aumento no número de idosos no meio rural. Diante desse fato, os autores concluem que o meio rural sofreu mudanças demográficas importantes, já que a presença de mulheres adultas indica o envelhecimento dessa população, formando um enorme contingente de idosas no campo.

Nesse sentido, a viuvez é predominante, já que as mulheres possuem uma maior longevidade em relação aos homens, porém, diferentemente dos homens, quando ficam viúvas, as mulheres não contraem um novo casamento, retornando para a casa dos filhos e auxiliando na renda com a aposentadoria (provedora), trabalho ou como cuidadoras dos netos. Para LloydSherlock (2004), as mulheres idosas possuem mais chances de ficarem viúvas e em situação socioeconômica desvantajosa do que os homens idosos.

Questionamos ainda nossos interlocutores sobre a divisão sexual do trabalho doméstico na família, sendo distribuído da seguinte forma: em 14 residências, as mulheres são as únicas responsáveis pela atividade; em três, toda a família realiza as atividades domésticas; em duas, as atividades são divididas entre o casal; e três entrevistados não quiseram responder. Podemos verificar que existe uma clara divisão sexual do trabalho doméstico, já que são as mulheres, em sua maioria, as responsáveis pela sua efetivação. Esse trabalho é tratado como algo inerente e natural ao gênero feminino. Trazemos algumas falas para exemplificar essa separação: "Ela é a responsável no serviço doméstico, eu me desvio, mas ajudo um pouco" (Entrevista 4); "Ela se vira" (Entrevista 5); "Lá em casa é a mãe e a cunhada que fazem o trabalho doméstico [...] Vem de tradição e afinidade pelo trabalho" (Entrevista 6); "A esposa tem tempo para isso" (Entrevista 8); "É a esposa [...] ela é a responsável, ela faz tudo" (Entrevista 9); "Eu tenho preguiça das coisas domésticas" (Entrevista 11). 
Ao analisarmos as falas dos entrevistados, teremos o trabalho doméstico e o cuidado com o lar como responsabilidades das mulheres, sendo refletido como uma divisão que ocorreu de forma "natural", como se houvesse uma maior aptidão das mulheres para o desenvolvimento destas funções. No entanto estas classificações reproduzem hierarquias e reduzem de forma simplória as várias atividades que podem ser exercidas pelas mulheres.

De acordo com Sorj (2008, p. 82), é nítido que "a predominância das mulheres nos afazeres domésticos ocorre em qualquer faixa de idade, inclusive entre as crianças e adolescentes. [...] Vê-se, nitidamente, que os padrões tradicionais de socialização de gênero persistem nas novas gerações". Dessa forma, historicamente, é possível verificar que as questões relacionadas ao trabalho doméstico são direcionadas como dever das mulheres.

Recorremos a Beauvoir (1967), autora reconhecida como referência na discussão de gênero e dos espaços femininos, para refletirmos sobre essa construção social. Para a autora, as tarefas domésticas são ensinadas e estimuladas desde a infância das meninas, por meio do brincar de boneca, de cozinhar, entre outros, e ao longo do crescimento, pelo auxílio direto nas atividades do lar junto às mães, sendo os meninos dispensados desses aprendizados e atividades:

É pelo trabalho doméstico que a mulher realiza a apropriação de seu "ninho"; eis por que, mesmo quando "se faz ajudar", quer pôr a mão na massa; vigiando, controlando, criticando, ela se esforça por tornar seus os resultados obtidos pelos servidores. Da administração de sua residência, tira sua justificação social; sua tarefa é também atentar para a alimentação, as roupas, e de uma maneira geral para a manutenção da sociedade familiar. Assim se realiza, ela também, como uma atividade. Mas trata-se, vamos vê-lo, de uma atividade que não a arranca de sua imanência, que não lhe permite uma afirmação singular de si própria. (BEAUVOIR, 1967, p. 197)

A divisão do trabalho vista como natural e/ou por identificação pela atividade parte do pressuposto de não existir a possibilidade de escolha, mas se define como algo imposto pelas construções sociais. Avaliamos que essas atividades separadas não se definem pela essência da atividade, e sim por quem a realiza. Corroborando com esta reflexão, trazemos Bourdieu (2012, p. 17), que define que:

A divisão entre os sexos parece estar "na ordem das coisas", como se diz por vezes para falar do que é normal, natural, a ponto de ser inevitável: ela está presente, ao mesmo tempo, em estado objetivado nas coisas (na casa, por exemplo, cujas partes são todas "sexuadas"), em todo o mundo social e, em estado incorporado, nos corpos e nos habitus dos agentes, funcionando como sistemas de esquemas de percepção, de pensamento e de ação.

Deste modo, é possível compreender as construções sociais arraigadas na sociedade e que acabam influenciando diretamente na sua organização. Atualmente, é possível verificar algumas transformações na reorganização das atividades em relação ao gênero, isso se deve pelo direito ao trabalho remunerado e o acesso ao estudo adquirido pelas mulheres. No entanto podemos verificar que no meio rural ainda prevalecem algumas das concepções relacionadas ao trabalho reprodutivo e ao trabalho produtivo, um associado ao gênero feminino e outro ao masculino. Conforme descreve Nobre (1998, p. 2):

[...] a divisão sexual do trabalho parte do princípio de que os homens são responsáveis pelo trabalho produtivo (a agricultura, a pecuária, enfim tudo o que se associa ao mercado) e as mulheres, pelo trabalho reprodutivo (o trabalho doméstico, o cuidado da horta e dos pequenos animais, tudo o que é feito para uso e consumo próprio, sem contar a reprodução da própria família pelo nascimento e cuidado dos herdeiros). 
Além da divisão sexual do trabalho, questionamos nossos interlocutores sobre a qualidade de vida das mulheres rurais, referindo-nos aos momentos dedicados às atividades de lazer. Como demonstram alguns estudos sobre o rural, a busca pelo lazer é um dos elementos decisórios para a saída do rural, principalmente para as jovens mulheres.

Para Paschoal (2000), a definição de qualidade de vida esteve por um tempo aliada ao econômico, ligada com as compras de bens materiais. Entretanto esse entendimento passou por várias críticas e a qualidade de vida veio a ser entendida, atualmente, de forma mais ampla, englobando o desenvolvimento social, a educação, a saúde e o lazer. Essa ideia contribui com o pensamento de Nahas (2001), ao relatar que a qualidade de vida atualmente está valorizada sob outros aspectos, tais como: a satisfação, realização pessoal, bem-estar, eventos culturais, relacionamentos e acesso ao lazer.

Todavia, quando deslocamos esses conceitos para o rural, deparamo-nos com a realidade do modo de vida típico do campo, onde o espaço dedicado ao trabalho e à vida/descanso são os mesmos, não existindo uma separação espacial ou temporal para a produção e para o lazer, ao contrário do que ocorre nos centros urbanos. Nesse sentido, perguntamos aos entrevistados o que eles compreendiam como lazer. Como respostas, obtivemos que a concepção de lazer está relacionada ao tempo livre, à realização de atividades das quais gostam e ao momento que não precisam realizar as atividades agropecuárias. Algumas das falas sobre o lazer foram: "Lazer é uma coisa boa, quando tem tempo" (Entrevistado 1); "Tempo à toa". "Não costumo sair muito". "Sou bem caseiro" (Entrevistado 2); "Fazer aquilo que dá prazer, alegria" (Entrevistado 6); "Quando não tá trabalhando, sai de casa, vai passear, sair passear já descansa" (Entrevistado 7); "Se divertir com a família, não fazer nada, ficar de boa" (Entrevistado 8); "Jogar baralho, não trabalhar, fazer o que gosta" (Entrevistado 9); "Lazer é não fazer nada" (Entrevistado 13); "Ficar de 'varde', não fazer nada, ficar em casa" (Entrevistado 18).

Nesse sentido, foram citados pelos entrevistados que as opções de lazer presentes na área rural do município são: os jogos de futebol, baralho, bocha, pescaria e bailes. Em relação às opções para as mulheres, foram citados: o clube das mães, visitas aos vizinhos, bailes, crochê e televisão. Porém, ao descreverem o que eles compreendem como lazer, podemos aferir que as opções para o rural acabam privilegiando os homens, deixando poucas opções para as mulheres.

Nesse sentido, as atividades de lazer para as mulheres estão ainda vinculadas às questões do lar, da família e do marido, tais como: a confecção de artesanato, a fabricação de pães, a frequência às missas, a participação do clube de mães, entre outras. De acordo com Schwengber e Pinheiro (2014, p. 77), o tempo de descanso e recreação da mulher está atrelado à programação e à organização dos filhos, pais, marido, netos, bem como no envolvimento com a comunidade por meio da organização das festas e das atividades religiosas. Ainda, as autoras apontam que:

Esta realidade se faz ainda muito presente, e parece que mais forte no meio rural, quando percebemos um envolvimento na feitura das festas, bem como uma diferença no trabalho de homens e mulheres. O espaço público é ocupado pelos homens, enquanto as mulheres ficam no espaço privado como o do lar. Antes da festa, os homens responsáveis por providenciar a carne reúnem-se para realizar a tradicional "carneança". E no dia da festa fica a cargo deles assar o churrasco, vender as "fichas" de almoço e de bebidas e contabilizar as despesas e lucros pós-festa. As mulheres reproduzem o espaço do lar: fazem pães e cucas, maionese, preparam saladas, fazem o arroz, os doces, organizam pratos e são responsáveis pela limpeza do salão; também se envolvem com a arrecadação e o sorteio de prêmios, com as lembrancinhas e a organização da missa. (SCHWENGBER; PINHEIRO, 2014, p. 77) 
No que se refere ao lazer para as mulheres, podemos observar que a rede das relações sociais está muito mais restrita do que as relações experimentadas e vivenciadas pelos homens. A pouca representatividade das mulheres nos contextos públicos possui relação direta com as normatizações estabelecidas desde crianças. Para Stropasolas (2004), as mulheres rurais, após o casamento, possuem menor acesso ao lazer, comparando com seus maridos. Além disso, segundo Aguiar e Stropasolas (2010, p. 164), "são as moças quem mais se ressentem da falta de lazer no meio rural. Via de regra, são os jovens homens quem têm acesso a formas mais variadas de lazer e maior autonomia para sair em busca de diversão".

A partir das percepções aqui relatadas, fica claro o protagonismo das mulheres na agricultura familiar. Entretanto, apesar desse protagonismo, podemos perceber que ainda é possível verificar o êxodo das mulheres rurais, principalmente das mais jovens. A falta de participação em espaços técnicos e a separação do trabalho produtivo e doméstico entre os gêneros podem intensificar essa saída das jovens mulheres que saem em busca de maior autonomia no espaço urbano. Para Silva e Mendes (2015, p. 237), é necessário entender a importância "[...] do trabalho da mulher no meio rural" como "[...] uma forma de garantir o desenvolvimento da agricultura familiar. Para que isso ocorra, há a necessidade de um conjunto de mudanças sociais e políticas que visem transformar as relações de gênero".

Nesse sentido, é necessário fomentar alternativas de participação e de empoderamento dessas mulheres, baseadas em assistência técnica, construção de políticas públicas e projetos que auxiliem na desmistificação do trabalho feminino, valorizando e reconhecendo o papel das mulheres para o desenvolvimento rural.

\section{ALGUMAS CONSIDERAÇÕES FINAIS}

Como reflexão diante do exposto, podemos ponderar sobre as diferenças entre os gêneros na área rural do município, pois elas são visíveis quando analisamos o processo de participação, permanência na propriedade e lazer das mulheres. Com isso, torna-se necessário um maior debate sobre as desigualdades vivenciadas pelas mulheres rurais, para que assim possamos construir alternativas que possibilitem o seu reconhecimento e sua maior participação social, visto que as organizações de mulheres camponesas em movimentos sociais já permitiram alguns avanços nesse sentido, como o reconhecimento enquanto agricultoras na Constituição de 1988. Longe de encerrarmos o debate sobre o papel e a representatividade das mulheres nas propriedades rurais, terminamos este trabalho com a necessidade de continuarmos a refletir e dialogar sobre as construções sociais, pois somente com novas percepções poderemos alcançar a igualdade e o reconhecimento das mulheres como trabalhadoras e protagonistas da agricultura familiar.

\section{REFERÊNCIAS}

ALCÂNTARA, Luciana Ruschel de. Idosos rurais: fatores que influenciam trajetórias e acesso a serviços de saúde no município de Santana da Boa Vista/RS. 2009. 156 f. Dissertação (Mestrado em Enfermagem) Universidade Federal do Rio Grande do Sul (UFRS), Porto Alegre, 2009.

AGUIAR, Vilenia Venancio Porto; STROPASOLAS, Vilmar Luiz. As problemáticas de gênero e geração nas comunidades rurais de Santa Catarina. In: SCOTT, Parry; CORDEIRO; Rosineide; MENEZES, Marilda (Org.). Gênero e geração em contextos rurais. Florianópolis: Ed. Mulheres, 2010. p. 159-83. 
AUGUSTO, Hélder dos Anjos; RIBEIRO, Eduardo Magalhães. O envelhecimento e as aposentadorias no ambiente rural: um enfoque bibliográfico. Revista Organizações Rurais e Agroindustriais, Lavras, MG, v. 7, n. 2, p. 199-208, 2005.

BATTISTI, Elisa. Redes sociais, identidade e variação linguística. In: FREITAG, Raquel Meister Ko (Org.). Metodologia de coleta e manipulação de dados em sociolinguística. São Paulo: Edgard Blücher, 2014. p. 79-98.

BEAUVOIR, Simone de. O segundo sexo: a experiência vivida. São Paulo: Difusão Europeia do Livro, 1967.

BOURDIEU, Pierre. A dominação masculina. Tradução Mari Helena Kühner. 11. ed. Rio de Janeiro: Bertrand Brasil, 2012.

BORDIEU, Pierre. O poder simbólico. 2. ed. Tradução Fernando Tomaz. Rio de Janeiro: Bertrand Brasil, 1998. $322 \mathrm{p}$.

CAMARANO, Ana Amélia. Mulher idosa: suporte familiar ou agente de mudança? Estudos Avançados, São Paulo, v. 17, n. 49, p. 35-63, set./dez. 2003.

FERREIRA, Brancolina; ALVES, Fábio. Juventude rural: alguns impasses e sua importância para a agricultura. In: CASTRO, Jorge Abrahão de; AQUINO, Luseni Maria Cordeiro de; ANDRADE, Carla Coelho de (Org.). Juventude e políticas sociais no Brasil. Brasília: Ipea, 2009. p. 243-58.

FROEHLICH, José Marcos; RAUBERL, Cassiane da Costa; CARPES, Ricardo Howes; TOEBE, Marcos. Êxodo seletivo, masculinização e envelhecimento da população rural na região central do RS. Ciência Rural, Santa Maria, RS, v. 41, n. 9, p. 1.674-1.680, set. 2011.

GIL, Antônio Carlos. Como elaborar projetos de pesquisa. 5. ed. São Paulo: Atlas, 2010.

GODOY, Cristiane Maria Tonetto. A emergência da identidade ambiental territorial na agricultura familiar nos municípios de Santa Rosa e Novo Machado, RS. 2015. 113f. Tese (Doutorado em Extensão Rural) Universidade Federal de Santa Maria, Santa Maria, RS, 2015.

GÓMEZ, Gregorio Rodríguez; FLORES, Javier Gil.; JIMÉNEZ, Eduardo García. Metodología de la investigación cualitativa. Málaga, Espanha: Ediciones Aljibe, 1996.

HECK, Rita Maria; LANGDON, Esther Jean Matteson. Envelhecimento, relações de gênero e o papel das mulheres na organização da vida em uma comunidade rural. In: MINAYO, Maria Cecilia de Souza; COIMBRA JUNIOR, Carlos Everaldo Alvares. (Org.). Antropologia, saúde e envelhecimento. Rio de Janeiro: Editora Fiocruz, 2002. p. 129-51.

INSTITUTO PARANAENSE DE DESENVOLVIMENTO ECONÔMICO E SOCIAL - IPARDES. Índice IPARDES de desempenho municipal: metodologia. Curitiba, 2018.

LLOYD-SHERLOCK, Peter. Viver mais tempo: envelhecimento, desenvolvimento e proteção social. [S.I.]: Livros Zed, 2004.

MAGALHÃES, Reginaldo Sales. A masculinização da produção de leite. Revista de Economia e Sociologia Rural, Brasília, v. 47, n. 1, p. 275-99, jan./mar. 2009.

MENASCHE, Renata; ESCHER, Maria Salete. Gênero e agricultura familiar: cotidiano de vida e trabalho na produção de leite. Curitiba: Comissão Estadual de Mulheres Trabalhadoras Rurais do Paraná, 1996.

NAHAS, Markus Vinicius. Atividade física, saúde e qualidade de vida: conceitos e sugestões para um estilo de vida ativo. Londrina, PR: Midiograf; 2001. 
NEVES, André Luis Alves et al. Caracterização dos produtores e dos sistemas de produção de leite no perímetro irrigado de Petrolina/PE. Revista Brasileira de Saúde e Produção Animal, Salvador, BA, v. 12, n. 1, p. 209-23, jan./mar. 2011.

NOBRE, Miriam. Relações de gênero e agricultura familiar. In: NOBRE, Miriam; SILIPRANDI, Emma; QUINTELA, Sandra; MENASCHE, Renata (Org.). Gênero e agricultura familiar. São Paulo: SOF, 1998. Disponível em: http://www.enfoc.org.br/system/arquivos/documentos/11/f1207relaes-de-genero-eagricultura-familiar---miriam-nobre.pdf. Acesso em: out. 2018.

OLIVEIRA, Lívia de. Percepção ambiental. In: SANTOS, Douglas Gomes dos; NUCCl, João Carlos (Org.). Paisagens geográficas: um tributo a Felisberto Cavalheiro. Campo Mourão, PR: Editora da FECILCAM, 2009. p. 153-63.

PASCHOAL, Sérgio Marcio Pacheco. Qualidade de vida do idoso: elaboração de um instrumento que privilegia sua opinião. 2000. 252 p. Dissertação (Mestrado em Medicina) - Universidade de São Paulo, São Paulo, 2000.

PAULILO, Maria Ignez Silveira. Trabalho familiar: uma categoria esquecida de análise. Estudos Feministas, Florianópolis, v. 12, n. 1, p. 229-52, jan./abr. 2004.

PAULILO, Maria Ignez Silveira; GRANDI, Alessandra Bueno de; SILVA, Marineide Maria. Mulher e a atividade leiteira: a dupla face da exclusão. In: PAULILO, Maria Ignez Silveira. Mulheres rurais: quatro décadas de diálogo. Florianópolis: Editora da UFSC, 2016. p. 15-70.

RIBEIRO, Jaime Moreira; SOUZA Francislê Neri de; LOBÃO, Catarina. Saturação da análise na investigação qualitativa: quando parar de recolher dados? Revista Pesquisa Qualitativa, São Paulo, v. 6, n. 10, p. III-VII, abr. 2018.

SALGADO, Carmen Delia Sánchez. Mulher idosa: a feminização da velhice. Estudos Interdisciplinares sobre o Envelhecimento, Porto Alegre, v. 4, p. 7-19, 2002.

SCHMITZ, Aline Motter; SANTOS, Roseli Alves dos. A divisão sexual do trabalho na agricultura familiar. In: SEMINÁRIO INTERNACIONAL FAZENDO GÊNERO, 10., 2013, Florianópolis. Anais [...]. Disponível em: http://www.fg2013.wwc2017.eventos.dype.com.br/resources/anais/20/1371853408_ARQUIVO_ TextoFazendogenero10.pdf. Acesso em: nov. 2018.

SCHWENGBER, Maria Simone Vione; PINHEIRO, Naíra Leticia Giongo Mandes. A tríade de lazer de mulheres camponesas do meio rural de Jóia (RS): atividades religiosas, rede de vizinhança e festas comunitárias. Gênero, Niterói, RJ, v. 15, n. 1, p. 69-80, 2014.

SILVA, Gabriela Bernardes; MENDES, Paula Pontes Estevane. As relações de gênero na agricultura familiar: a comunidade Ribeirão no município de Catalão (GO). In: NEVES, Adriana Freitas; FERREIRA, Idelvone Mendes; PAULA, Maria Helena de; ANJOS, Petrus Henrique Ribeiro dos (Org.). Coletânea interdisciplinar em pesquisa, pós-graduação e inovação. 1. ed. São Paulo: Edgard Blücher, 2015. v. 1, p. 229-40.

SILVA, Carolina Braz de Castilho; SCHNEIDER, Sérgio. Gênero, trabalho rural e pluriatividade. In: SCOTT, Parry; CORDEIRO, Rosineide; MENEZES, Marilda (Org.). Gênero e geração em contextos rurais. Florianópolis: Ed. Mulheres, 2010. p. 183-207.

SORJ, Bila. O trabalho doméstico e de cuidados: novos desafios para a igualdade de gênero no Brasil. In: SILVEIRA, Maria Lucia da; TITO, Neuza. Trabalho doméstico e de cuidados: por outro paradigma de sustentabilidade da vida humana (Org.). São Paulo: Sempre Viva Organização Feminista, 2008. p. 77-89.

STROPASOLAS, Valmir Luiz. O valor (do) casamento na agricultura familiar. Estudos Feministas, Florianópolis, v. 12, n. 1, p. 253-67, jan./abr. 2004. 
TURATO, Egberto Ribeiro. Tratado da metodologia da pesquisa clínico-qualitativa: construção teóricoepistemológica, discussão comparada e aplicação nas áreas da saúde e humanas. 2. ed. Petrópolis, RJ: Vozes, 2003.

\section{Sobre os autores:}

Clair Odete Schneider: Pós-Graduanda stricto sensu no Programa de Desenvolvimento Regional (PPGDR) da Universidade Tecnológica Federal do Paraná (UTFPR). Bolsista da Coordenação de Aperfeiçoamento de Pessoal de Nível Superior (CAPES). Especialista em Avaliação Psicológica e Diagnóstico pela Universidade do Oeste de Santa Catarina (UNOESC). Graduada em Psicologia pela Universidade Comunitária da Região de Chapecó (UNOCHAPECÓ). Pesquisadora do grupo "Gênero, Juventude e Cartografias da Diferença" da UTFPR. E-mail: clair-schneider@unochapeco.edu.br, Orcid: http://orcid.org/0000-0002-3327-5102

Cristiane Maria Tonetto Godoy: Doutora pelo Programa de Pós-Graduação em Extensão Rural, atualmente bolsista de pós-doutorado no Programa de Pós-Graduação em Desenvolvimento Regional da Universidade Tecnológica Federal do Paraná (UFTPR), campus Pato Branco. Mestre em Extensão Rural pela Universidade Federal de Santa Maria (UFSM). Graduada em Agronomia pela UFSM. Tem experiência na área de Agronomia, atuando principalmente nos seguintes temas: agricultura familiar, agroecologia, educação ambiental, desenvolvimento rural sustentável e percepção ambiental, identidades e territórios ambientais. E-mail: guriaccr@hotmail.com, Orcid: http://orcid.org/0000-0001-6150-9976.

Josiane Carine Wedig: Doutora pelo Programa de Pós-Graduação de Ciências Sociais em Desenvolvimento, Agricultura e Sociedade da Universidade Federal Rural do Rio de Janeiro (UFRRJ). Realizou doutorado-sanduíche na École des Hautes Études en Sciences Sociales (EHESS), Paris. Mestre pelo Curso de Pós-Graduação em Desenvolvimento Rural pela Universidade Federal do Rio Grande do Sul (UFRGS). Licenciada e bacharel em Ciências Sociais pela Universidade Federal de Pelotas (UFPel). Professora de Sociologia do Departamento de Ciências Humanas e do Mestrado em Desenvolvimento Regional (PPGDR) da Universidade Tecnológica Federal do Paraná (UTFPR). É líder do Grupo de Pesquisa: Gênero, Juventude e Cartografias da Diferença (PPGDR/ UTFPR). E-mail: josianewedig@utfpr.edu.br, Orcid: http://orcid.org/0000-0002-5162-3158

Thiago de Oliveira Vargas: Doutor SWE/CNPq Department of Environmental Studies, University of California at Santa Cruz (2011-2012). Doutor em Fitotecnia (Produção Vegetal) e mestre em Fitotecnia pela Universidade Federal de Viçosa (UFV). Graduado em Agronomia pela Universidade Federal Rural do Rio de Janeiro (UFRRJ). Professor adjunto da Universidade Tecnológica Federal do Paraná (UTFPR), campus Pato Branco. Professor permanente dos Programas de Pós-Graduação em Agronomia (PPGAG) e Desenvolvimento Regional (PPGDR) da UTFPR, campus Pato Branco. É membro das Associações Brasileiras de Agroecologia (ABA) e Horticultura (ABH). Tem experiência na área de Agronomia, com ênfase em agroecologia e produção orgânica de plantas, atuando principalmente nos seguintes temas: olericultura, melhoramento genético do tomateiro, desempenho de cultivares no sistema orgânico de produção, adubação verde, fixação biológica de nitrogênio, sistema de plantio direto de hortaliças (SPDH), plantas alimentícias não convencionais (PANCs, hortaliças não convencionais, hortaliças tradicionais), hortaliças nutracêuticas. E-mail: thiagovargas@utfpr.edu.br, Orcid: http://orcid.org/0000-0003-3665-5917 